\title{
The Impact of Federal Policy Changes and Initiatives on Breastfeeding Initiation Rates and Attitudes Toward Breastfeeding Among WIC Participants
}

\author{
Anthony Dominic Panzera, PhD, MPH; Karen Castellanos-Brown, PhD, MSW; \\ Courtney Paolicelli, DrPH, RDN, LD, CDE; Ruth Morgan, MPH; \\ Anna Potter, MPP; Danielle Berman, PhD
}

\begin{abstract}
To explore the effects of the Special Supplemental Nutrition Program for Women, Infants, and Children (WIC) on participants' breastfeeding $(\mathrm{BF})$ practices, studies that use large national samples are warranted. The US Department of Agriculture's Food and Nutrition Service funded several studies that leveraged national samples of WIC agencies, sites, and participants to evaluate how WIC affects BF outcomes among its participants. This report integrates findings across multiple Food and Nutrition Service-funded studies to describe important program benefits and how the program and its benefits supported positive attitudes and beliefs toward BF, as well as higher rates of BF initiation. The report concludes with policy implications and suggestions for future research.
\end{abstract}

Key Words: WIC, breastfeeding, food package, initiation, duration (J Nutr Educ Behav. 2017;49:S207-S211.)

Accepted April 30, 2017.

\section{INTRODUCTION}

Among the myriad of short-term and long-term health benefits breastfeeding (BF) may confer, children who are breastfed are less likely to develop infections during infancy and chronic diseases later in childhood. ${ }^{1-3}$ Breastfeeding also reduces a women's risk for breast and ovarian cancers and type 2 diabetes. ${ }^{2}$ Given these important health benefits, the American Academy of Pediatrics recommends that infants breastfeed exclusively for the first 6 months and for at least the first 12 months of age. ${ }^{4}$ In its efforts to safeguard the nutrition and health of low-income women, infants, and young children, the Special Supplemental Nutrition Program for Women, Infants, and Children (WIC) provides comprehensive nutri- tion education and BF support to enrolled participants. In 2014, 9.3 million individuals were certified to receive WIC benefits; in 2015, nearly half of all infants in the US participated in WIC. To support WIC in providing evidencebased services, the Office of Policy Support within the Food and Nutrition Service (FNS) at the US Department of Agriculture administers a portfolio of studies to evaluate program participation, operations, costs, and regulatory impact, as well as participants' attitudes, behaviors, and health outcomes.

This report synthesizes findings from a number of recent FNS studies to document the multifaceted impact of WIC on BF practices (Table). The largest of these efforts is the WIC Infant and Toddler Feeding Practices Study-2 (WIC ITFPS-2), a longitudinal study

Office of Policy Support, Food and Nutrition Service, US Department of Agriculture, Alexandria, VA

Conflict of Interest Disclosure: The authors' conflict of interest disclosures can be found online with this article on www.jneb.org.

Address for correspondence: Courtney Paolicelli, DrPH, RDN, LD, CDE, Office of Policy Support, Food and Nutrition Service, 3101 Park Center Dr, Rm 1014, Alexandria, VA 22302; Phone: (703) 605-4370; Fax: (703) 305-2017; E-mail: Courtney.Paolicelli@fns.usda.gov Published by Elsevier, Inc. on behalf of the Society for Nutrition Education and Behavior. http://dx.doi.org/10.1016/j.jneb.2017.04.026

Journal of Nutrition Education and Behavior • Volume 49, Number 7S2, 2017

involving a nationally representative sample of 4,367 mother-infant dyads observed from enrollment in WIC in the prenatal or early postpartum period through the child's fifth birthday. ${ }^{5}$ The WIC ITFPS-2 collects feeding practice and dietary data from study participants every 2-6 months using 24-hour dietary recalls and telephone interviews. Findings from the current study are compared with those from the WIC Infant Feeding Practices Study1 (WIC IFPS-1) ( $\mathrm{n}=874$ motherinfant dyads), ${ }^{6}$ an FNS-funded study conducted in the mid-1990s; however, owing to data limitations, significance testing between the 2 studies is not possible. Nonetheless, much of the study design, methods, and instruments from WIC ITFPS-2 were modeled after WIC IFPS-1; thus, comparisons between the studies can be used to demonstrate the magnitude of improvements observed over the past 2 decades.

The WIC Breastfeeding Peer Counseling Phase II Study (BFPC-II), ${ }^{7}$ which was conducted in 2014, provided updated information on the implementation of the Loving Support peer counseling (PC) program and made comparisons with a previous study conducted in 2008 . 
Table. Characteristics of Recent Food and Nutrition Service Studies Investigating WIC's Impact on BF Practices

\begin{tabular}{|c|c|c|c|c|c|}
\hline Study Name & $\begin{array}{c}\text { Study } \\
\text { Contractor }\end{array}$ & Study Description & $\begin{array}{c}\text { Data } \\
\text { Collection } \\
\text { Time Frame }\end{array}$ & $\begin{array}{l}\text { Data Sources and } \\
\text { Sample Sizes }\end{array}$ & $\begin{array}{l}\text { Types of Data } \\
\text { Collected }\end{array}$ \\
\hline $\begin{array}{l}\text { WIC Infant and } \\
\text { Toddler Feeding } \\
\text { Practices Study-2 } \\
\text { (WIC ITFPS-2, or } \\
\text { Feeding My } \\
\text { Baby Study) }\end{array}$ & Westat & $\begin{array}{l}\text { 5-y longitudinal study of } \\
\text { nationally } \\
\text { representative } \\
\text { sample of infants } \\
\text { participating in WIC }\end{array}$ & 2013-present & $\begin{array}{l}\text { - } 27 \text { WIC state } \\
\text { agencies (SAs) } \\
\text { - } 80 \text { local WIC sites } \\
\text { - } 4,367 \text { mother-infant } \\
\text { dyads }\end{array}$ & $\begin{array}{l}\text { - State and local } \\
\text { agency program } \\
\text { characteristics } \\
\text { - Dietary intake and } \\
\text { feeding practices } \\
\text { of infants/children } \\
\text { enrolled in WIC }\end{array}$ \\
\hline $\begin{array}{l}\text { WIC Breastfeeding } \\
\text { Peer Counseling } \\
\text { Phase II Study } \\
\text { (BFPC-II) }\end{array}$ & $\begin{array}{l}\text { Abt } \\
\text { Associates }\end{array}$ & $\begin{array}{l}\text { Descriptive survey that } \\
\text { provided updated } \\
\text { information on } \\
\text { implementation of } \\
\text { Loving Support PC } \\
\text { program and made } \\
\text { comparisons with } \\
\text { study conducted in } \\
2008\end{array}$ & 2014 & $\begin{array}{l}\text { - } 50 \text { WIC SAs (not } \\
\text { including ITOs or } \\
\text { territories) } \\
\text { - WIC PC } 2012 \text { study } \\
\text { data }\end{array}$ & $\begin{array}{l}\text { - Program operations } \\
\text { and allocation of } \\
\text { resources } \\
\text { - SAs' role in } \\
\text { BF promotion } \\
\text { - LA Loving Support } \\
\text { program data from } \\
\text { WIC SAs }\end{array}$ \\
\hline $\begin{array}{l}\text { WIC Breastfeeding } \\
\text { Policy Inventory } \\
\text { (WIC BPI) }\end{array}$ & $\begin{array}{l}\text { Mathematica } \\
\text { Policy } \\
\text { Research }\end{array}$ & $\begin{array}{l}\text { A 2-phase online } \\
\text { census survey of SAs } \\
\text { (including ITOs and } \\
\text { US Territories) and } \\
\text { LAs }\end{array}$ & 2013 & $\begin{array}{l}\text { - } 82 \text { WIC SAs, } \\
\text { including } 50 \text { states, } \\
\text { DC, } 3 \text { territories, and } \\
28 \text { ITOs } \\
\text { - } 1,662 \text { WIC LAs }\end{array}$ & $\begin{array}{l}\text { - BF policies and } \\
\text { practices } \\
\text { - BF measures in use } \\
\text { by SAs and LAs }\end{array}$ \\
\hline $\begin{array}{l}\text { WIC Participant and } \\
\text { Characteristics } \\
\text { Report }\end{array}$ & $\begin{array}{l}\text { Insight Policy } \\
\text { Research }\end{array}$ & $\begin{array}{l}\text { Census of individuals } \\
\text { enrolled in WIC in } \\
\text { April of the reporting } \\
\text { year, using state } \\
\text { agency-collected } \\
\text { enrollment data to } \\
\text { provide information } \\
\text { on participant } \\
\text { income and nutrition } \\
\text { risk characteristics, } \\
\text { estimate } \\
\text { breastfeeding } \\
\text { initiation rates for } \\
\text { WIC infants, and } \\
\text { describe WIC } \\
\text { members of migrant } \\
\text { farm worker families. }\end{array}$ & $\begin{array}{l}2014 \text { (report } \\
\text { generated } \\
\text { biennially } \\
\text { since 1992) }\end{array}$ & $\begin{array}{l}\text { - } 90 \text { WIC SAs, } \\
\text { including } 50 \text { states, } \\
\text { DC, } 5 \text { territories, and } \\
34 \text { ITOs } \\
\text { - 9,303,253 WIC } \\
\text { certified enrollees } \\
\text { (from April, 2014) }\end{array}$ & $\begin{array}{l}\text { - Enrollment } \\
\text { information } \\
\text { - Income } \\
\text { - Nutrition risk } \\
\text { - BF measures }\end{array}$ \\
\hline
\end{tabular}

BF indicates breastfeeding; ITO, Indian Tribal Organization; LA, local agency; PC, peer counseling; SA, state agency; WIC, Special Supplemental Nutrition Program for Women, Infants, and Children.

The results showed how significantly increased funding in 2010, and to a lesser extent 2014, contributed to access to and provision of BF support and PC services.

The WIC Breastfeeding Policy Inventory (WIC BPI), ${ }^{8}$ which was conducted in 2013, used a 2-phase online survey to collect data on BF policies and practices and the BF measures in use by state agencies (SAs) and local agencies (LAs). This study was the first to highlight the variety of policies and practices that SAs and LAs used to promote and support BF.

In addition to these evaluationoriented data collection efforts, FNS also publishes the biennial WIC Participant and Program Characteristics report, ${ }^{9}$ which uses a census of administrative data from all women, infants, and children certified to receive WIC benefits in April of the study year. The WIC Participant and Program Characteristics report series includes administrative data on $\mathrm{BF}$ initiation and duration going back to 1998 , which allows the analysis and monitoring of trends in program and participant measures over time.

This article uses several large national studies to highlight findings on important benefits of WIC; changes in attitudes toward, beliefs about, and intentions to breastfeed; and $\mathrm{BF}$ initiation and duration rates among mothers enrolled in WIC. Policy implications of these findings are made within the context of $\mathrm{BF}$ 
support, and future research directions are suggested.

\section{SUMMARY OF FINDINGS}

\section{Program Benefits}

WIC provides 7 broad food packages for women, infants, and children that vary in types and amounts of food. Current WIC food packages (implemented in 2009 and finalized in 2014) are designed to incentivize mothers to breastfeed by providing healthy foods to mothers who exclusively or partially breastfeed to meet their nutritional needs. This includes a greater quantity and variety of healthy foods such as juice, milk, and whole-wheat bread. ${ }^{10}$ Administrative data from fiscal year (FY) 2015 indicated that women receiving the fully or partially BF food package outnumbered women receiving the postpartum, nonBF food packages $(593,557$ compared with 557,463). ${ }^{11}$ Program staff are uniquely positioned to provide information to participants where there are opportunities to breastfeed, and, in some circumstances ${ }^{12}$ to tailor individual food packages to meet nutritional needs. $^{13}$

Findings from the WIC BPI study indicated that more than three quarters of LAs and direct service SAs informed pregnant participants about the greater quantity and variety of foods in the fully BF food package (86\% and $87 \%$, respectively); findings were similar for women who enrolled in WIC after giving birth. The WIC ITFPS-2: Infant Year Report found that among BF mothers who were aware of the fully BF food package at 3 months postpartum, $61 \%$ said that the food package had an important role in their decision to breastfeed. ${ }^{6}$

\section{Support for BF}

The Loving Support PC program is a WIC initiative that supports and encourages $\mathrm{BF}$ among mothers enrolled in WIC. Findings from BFPC-II documented how increased Loving Support PC annual funding (pre-FY 2010, \$15 million; FY 2010, \$80 million; and FY 2014, \$60 million) enabled WIC agencies to expand access substantially to PC services. The percentage of LAs operating Loving Support across the nation increased dramatically from $33 \%$ to $70 \%$ between 2008 and 2014. Whereas the
2008 study (BFPC-I) found that about $46 \%$ of pregnant WIC participants were served by LAs with Loving Support, almost twice as many (87\%) pregnant participants had access to the program by 2014 .

The WIC BPI further quantified the reach of BF PC programs, focusing on the reach of any PC programs aiming to improve BF outcomes. Specifically, the study indicated that $93 \%$ of SAs reported operating or overseeing LAs with PC programs, and 69\% of LAs reported operating a PC program. $^{8}$ Among LAs that operated PC programs, the program was available in $83 \%$ of their clinic sites on average; these LAs served $86 \%$ of the WIC population. ${ }^{8}$ In addition, over $90 \%$ of WIC participants at LAs with PC programs could access such services prenatally and LAs most often referred mothers who encountered problems with BF to health care providers $(86.7 \%)$, lactation professionals (76.0\%), or BF support organizations $(74.4 \%){ }^{8}$ The WIC BFPC-II study also revealed that $60 \%$ of SAs reported efforts to make lactation consultants available to WIC participants in 2014, compared with $43 \%$ in $2008 .^{8}$ These findings point to increased access to BF support through PC and referrals for mothers enrolled in WIC.

The availability of trained WIC staff and $\mathrm{BF}$ peer counselors is intended to increase participants' knowledge of $\mathrm{BF}$ and its related benefits, and in turn improve BF initiation rates and duration. The WIC BPI study found that about $78 \%$ of LAs had at least 1 staff member with certification in lactation counseling, consulting, education, or management. In addition to providing ongoing training to nearly all local-level peer counselors (97\%), 60\% of LAs provided WIC clerical and support staff with ongoing BF promotion training and $46 \%$ received this training at least annually. The WIC BFPC-II study documented the growing significance of the International Board Certified Lactation Consultant or other lactation management training or certification for PC coordinators between 2008 and 2014. Similarly, more SAs in 2014 than in 2008 recommended or required LAs to conduct a formal performance evaluation of their peer counselors. These findings suggest that WIC staff members who provide BF support are highly trained and that the program supports the professional nature of staff in this area.

In the WIC ITFPS-2: Intentions to Breastfeed Report (ie, the Prenatal Report), $72 \%$ of women reported receiving $\mathrm{BF}$ information from WIC during the prenatal period. ${ }^{5}$ A total of $68 \%$ of women reported talking to WIC staff about BF, which was more than the percentage of women who spoke to their mothers $(62 \%)$ or doctors (51\%) about BF. ${ }^{5}$ As documented in the Infant Year Report, about half of mothers turned to WIC for assistance when BF problems arose. ${ }^{14}$ These findings indicated that WIC offers information about BF to most of its prenatal participants and that many postnatal participants rely on WIC for information related to $\mathrm{BF}$.

Local agencies further supported BF by encouraging the practice in their clinics and communities. Nearly all LAs (98\%) maintained a BF-friendly environment by encouraging participants to breastfeed anywhere in the clinic, and $88 \%$ provided a private space for BF. ${ }^{8}$ The support of WIC for BF also extended beyond WIC sites; about $89 \%$ collaborated with or extended outreach on BF promotion and support activities to hospitals, clinics, or doctors' offices, including one third that provided in-hospital BF support to mothers enrolled in WIC. ${ }^{8}$

\section{Attitudes and Intentions to Breastfeed}

FNS has monitored changes in correlates of BF initiation, such as participants' attitudes and intentions to breastfeed, to demonstrate how the attitudes of WIC recipients have changed over time. Women participating in WIC IFPS-2 had more favorable beliefs about BF and the benefits of BF compared with those participating in WIC ITFPS1; they also reported fewer barriers to BF. More women agreed that breastfed babies are healthier than formula-fed babies in WIC ITFPS-2, compared with those in WIC IFPS-1 (80\% and 61\%, respectively). In addition, the proportion of WIC mothers agreeing with statements about BF barriers decreased between the 2 studies. Over the 2 decades between WIC IFPS-1 and WIC ITFPS-2, the percentage of women agreeing with the statement $B F$ ties you down decreased from $41 \%$ to $17 \%$ and the percentage of women agreeing 
with the statement BF takes too much time decreased from $34 \%$ to $15 \% .^{14}$

The WIC ITFPS- 2 evaluated prenatal women's BF intentions using the infant feeding intentions (IFI) scale, which ranged from 0 (strong intention not to breastfeed) to 16 (strong intention to breastfeed). ${ }^{15}$ Only $26 \%$ of women had low or very low IFI scores whereas 39\% had moderate scores and 35\% had high or very high scores. African American women, women who were pregnant with a second child, women who previously received WIC, women who did not live with the baby's father, and women who discussed infant feeding plans with no more than 1 person all had lower IFI scores than did their counterparts. ${ }^{5}$

\section{Initiation and Duration of $\mathrm{BF}$}

Whereas measuring intention captures plans to begin $\mathrm{BF}$, initiation rates document when those plans are put into action. Recent estimates of the proportion of infants in the US who are breastfed (eg, 51\% prevalence of BF at 6 months in 2012, a 4\% increase from 2010) demonstrated the nation's steady movement toward meeting Healthy People 2020 targets, including Maternal, Infant and Child Health (MICH) indicators 21.1-5, that aimed to increase both the proportion of infants ever breastfed and proportion of infants who exclusively breastfeed. ${ }^{16}$ Yet lower $\mathrm{BF}$ rates were seen among families with the lowest income. ${ }^{17}$ Because WIC's target population is low-income women and children, WIC has continued to make BF support and promotion one of its primary services.

Drawing on administrative data, the 2014 WIC Participant and Program Characteristics report found that the BF initiation rate among infants and children aged 6-13 months was $69.8 \%$, a $2.7 \%$ increase over the rate observed in 2012 and a continuation of the overall upward trend in $\mathrm{BF}$ initiation observed since this measure was initially reported in 1998 . The WIC ITFPS- 2 also found that BF initiation rates have increased since the mid-1990s. ${ }^{14}$ In 2013, the BF initiation rate among women enrolled in the longitudinal study sample was $83 \%$; this rate was nearly 1.5 times the rate from WIC IFPS-1 (56\%). The difference in the $\mathrm{BF}$ initiation rates observed between the WIC Participant and Program Characteristics report and WIC ITFPS- 2 primarily resulted from differences in study methodologies and analytic techniques. Nonetheless, both studies demonstrated that BF initiation rates among WIC infants were increasing.

In terms of BF duration, the percentage of women receiving WIC who continue to breastfeed (exclusively or in combination with formula) rose notably since WIC IFPS-1. At 1 month postpartum, the percentage of women $\mathrm{BF}$ increased by $85 \%$ (from $33 \%$ in WIC IFPS-1 to $61 \%$ in WIC ITFPS-2), and between 3 and 12 months postpartum, the BF rates more than doubled since the first study (ie, in WIC IFPS-1 the rate was $21 \%$ at 3 months and $7 \%$ at 12 months, but in WIC ITFPS- 2 the rate was $42 \%$ at 3 months and $18 \%$ at 12 months).

The WIC Participant and Program Characteristics report also includes measures of BF duration among women enrolled in WIC. In 2014, the WIC Participant and Program Characteristics report showed that the median BF duration observed among infants and children aged 6-13 months was 13 weeks. ${ }^{9}$ The proportion of infants BF for $\geq 6$ months was estimated between $23.3 \%$ and $30.6 \%$. $^{9}$ Data from the 1-month postpartum interview of WIC ITFPS- 2 revealed that the majority of BF mothers (73\%) planned to breastfeed for $>6$ months. ${ }^{14}$ However, by the fifth-month interview, many respondents who had planned to breastfeed for $>6$ months had already stopped $\mathrm{BF}$, and $69 \%$ stated that they had not breastfed for as long as they had originally intended. ${ }^{14}$ Together, the findings from the WIC Participant and Program Characteristics report and WIC ITFPS-2 indicated that although many women breastfeed their infants, the median duration of $\mathrm{BF}$ is $<6$ months and many women are not meeting their intended BF goals.

\section{IMPLICATIONS FOR RESEARCH AND PRACTICE}

FNS studies revealed an increase in BF rates among WIC recipients over the past 2 decades. These studies also demonstrate increased access to BF PC services, increased support for BF, and improvements in attitudes and beliefs about BF. These improvements occurred as WIC strengthened its BF promotion and support efforts through WIC food package changes and the WIC Loving Support BF PC program. Although the FNS research portfolio provides an evidence base for WIC services, there are opportunities for nutrition educators, researchers, and public health practitioners to expand on FNS findings and explore additional research questions related to WIC's impact on BF outcomes.

Rasmussen et $\mathrm{al}^{18}$ noted that additional research was warranted in the development of universal BF indicators. The WIC BPI laid the groundwork for developing universal BF indicators by gathering information on how the 4 main BF outcomes (initiation, duration, exclusivity, and intensity) were measured by LAs. In particular, BF intensity was considered the most difficult outcome to capture and report; only half of LAs collected information on BF intensity whereas almost all LAs collected information on BF initiation, duration, and exclusivity. ${ }^{8}$ Further research could identify the best ways to capture BF intensity.

Another area that warrants additional research is the extent to which WIC's PC and BF support programs affect BFinitiation and duration. Currently, SAs and LAs have the flexibility to adapt their programs to meet the needs of their service populations; as such, the elements of these programs may vary by location. Local- and nationallevel research could be used to identify which program elements are associated with favorable outcomes. In addition, nutrition educators and practitioners might use these findings to develop practical guidance materials to instruct WIC sites on adapting and potentially incorporating these elements into their current operations.

\section{ACKNOWLEDGMENTS}

The authors would like to acknowledge and thank Kelly Scanlon, Division Director of the Special Nutrition Research and Evaluation Division; and Melissa Abelev, Assistant Deputy Administrator in the Office of Policy Support, for a careful review of the full manuscript. 


\section{REFERENCES}

1. Horta B, Victora C. Long-term effects of breastfeeding: a systematic review. World Health Organization, Full Report 2013:67-68. http://apps.who. int/iris/bitstream/10665/79198/1/978924 1505307_eng.pdf. Accessed April 26, 2017.

2. Section on Breastfeeding. Breastfeeding and the use of human milk. Pediatrics. 2012;129:e827-e841.

3. Victora CG, Bahl R, Barros AJD, et al. Breastfeeding in the $21^{\text {st }}$ century: epidemiology, mechanisms, and lifelong effect. Lancet. 2016;387:475-490.

4. Ip S, Chung M, Raman G, et al. Breastfeeding and maternal and infant health outcomes in developed countries. Evid Rep Technol Assess (Full Rep). 2007; 153:1-186.

5. May L, Borger C, McNutt S, et al. WIC Infant and Toddler Feeding Practices Study 2: intention to breastfeed. 2015. www.fns.usda.gov/research-andanalysis. Accessed April 26, 2017.

6. Bayder N, McCann M, Williams R, Vesper E. Final report: WIC Infant Feeding Practices Study. Food and Nutrition Service, US Department of
Agriculture. https://www.fns.usda.gov/ sites/default/files/WICIFPS.pdf. Accessed January 24, 2017.

7. Epstein C, Collins A. WIC Breastfeeding Peer Counseling Study: Phase II follow up implementation report, http://www. fns.usda.gov/ops/wic-studies. Accessed April 26, 2017.

8. Forrestal S, Briefel R, Mabli J. WIC Breastfeeding Policy Inventory. http:// www.fns.usda.gov/research-and-analy sis. Accessed April 26, 2017.

9. Thorn B, Tadler C, Huret N, et al. WIC Participant and Program Characteristics 2014. Alexandria, VA: US Department of Agriculture, Food and Nutrition Service; 2015.

10. Food and Nutrition Service. WIC food packages-maximum monthly allowances. https://www.fns.usda.gov/wic/ wic-food-packages-maximum-monthlyallowances. Accessed April 26, 2017.

11. US Department of Agriculture, Food and Nutrition Service. National Data Bank [internal]. Accessed January 11, 2017.

12. Food and Nutrition Service. Food Package Policy and Guidance: A Guide for FNS Regional Offices, and WIC State and Local Agencies. Alexandria, VA: US Dept of Agriculture; 2016:18-19.
13. US Department of Agriculture, Food and Nutrition Service. Supplemental Foods. 2016. 7 CFR S 246.10 (c).

14. May L, Borger C, McNutt S, et al. WIC Infant and Toddler Feeding Practices Study 2: Infant Year Report. 2016. www.fns.usda.gov/research-and-analysis. Accessed April 26, 2017.

15. Nommsen-Rivers LA, Dewey KG. Development and validation of the infant feeding intentions scale. Maternal Child Health J. 2009;13:334-342.

16. Department of Health and Human Services. Maternal, infant, and child health. https://www.healthypeople.gov/2020/ topics-objectives/topic/maternal-infantand-child-health/objectives. Accessed December 10, 2016.

17. Anstey EH, MacGowan CA, Allen JA. Five-year progress update on the Surgeon General's call to action to support BF, 2011. J Womens Health. 2016;25:768-776.

18. Rasmussen KM, Whaley SE, Baker SS, et al. Review of WIC food packages: improving balance and choice: final report. http://www.nationalacademies. org/hmd/Reports/2017/review-of-wicfood-packages-improving-balance-andchoice.aspx. Accessed April 26, 2017.

\section{Guest Editor Spotlight: Dr. Madeleine Sigman-Grant}

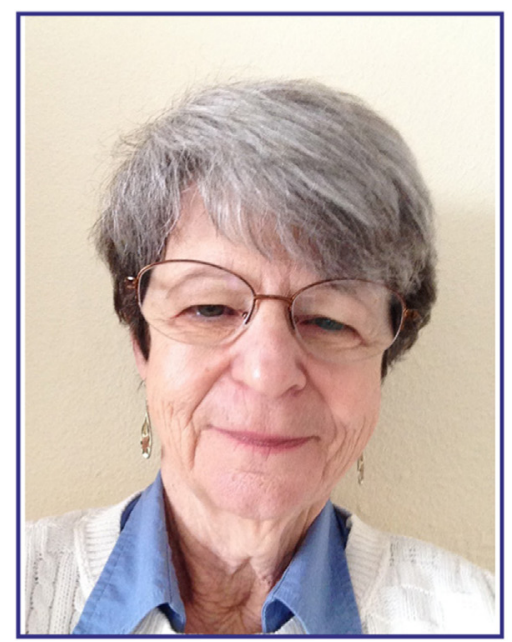

As a Maternal and Child Health and Nutrition Specialist since 1977, Dr. Sigman-Grant brought her wealth of experience and knowledge to the role of Guest Editor for this JNEB Supplemental Issue. Although retired from academia, Dr. Sigman-Grant is still active as a consultant and technical writer. Her skills as a researcher and practitioner combined to coordinate a smooth publication process. Dr. Sigman-Grant also serves as an Associate Editor of the Journal of Nutrition Education and Behavior. 


\section{CONFLICT OF INTEREST}

The authors have not stated any conflicts of interest. 